\title{
Insulin-induced hypoglycemia increases hepatic sensitivity to glucagon in dogs
}

\author{
Noelia Rivera, ${ }^{1}$ Christopher J. Ramnanan, ${ }^{1}$ Zhibo An, ${ }^{1}$ Tiffany Farmer, ${ }^{1}$ Marta Smith, ${ }^{1}$ Ben Farmer, ${ }^{1}$ \\ Jose M. Irimia, ${ }^{2}$ Wanda Snead, ${ }^{1}$ Margaret Lautz, ${ }^{1}$ Peter J. Roach, ${ }^{2}$ and Alan D. Cherrington'
}

1Department of Molecular Physiology, Vanderbilt University School of Medicine, Nashville, Tennessee, USA. 2Department of Biochemistry and Molecular Biology, Indiana University School of Medicine, Indianapolis, Indiana, USA.

\begin{abstract}
In individuals with type 1 diabetes, hypoglycemia is a common consequence of overinsulinization. Under conditions of insulin-induced hypoglycemia, glucagon is the most important stimulus for hepatic glucose production. In contrast, during euglycemia, insulin potently inhibits glucagon's effect on the liver. The first aim of the present study was to determine whether low blood sugar augments glucagon's ability to increase glucose production. Using a conscious catheterized dog model, we found that hypoglycemia increased glucagon's ability to overcome the inhibitory effect of insulin on hepatic glucose production by almost 3-fold, an effect exclusively attributable to marked enhancement of the effect of glucagon on net glycogen breakdown. To investigate the molecular mechanism by which this effect comes about, we analyzed hepatic biopsies from the same animals, and found that hypoglycemia resulted in a decrease in insulin signaling. Furthermore, hypoglycemia and glucagon had an additive effect on the activation of AMPK, which was associated with altered activity of the enzymes of glycogen metabolism.
\end{abstract}

\section{Introduction}

In individuals with type 1 diabetes, hypoglycemia is a common consequence of overinsulinization. The incidence of hypoglycemia is less frequent in individuals with type 2 diabetes, but as the disease progresses and patients begin to use insulin, it once again becomes a limiting factor in glycemic control (1). The counterregulatory response to hypoglycemia in the normal individual involves the release of glucagon, epinephrine, norepinephrine, cortisol, and growth hormone, which together increase glucose production and limit glucose utilization (2). Glucagon has been shown to provide the primary stimulus for the counterregulatory increase in glucose production in response to insulin-induced hypoglycemia in the normal individual (2). Furthermore, abnormalities in the response of the $\alpha$ cell to hypoglycemia make individuals with diabetes more prone to low blood sugar $(1,2)$.

We have previously examined the interaction between insulin and glucagon in controlling glucose production in the conscious $\operatorname{dog}(3)$. Intraportal replacement of basal amounts of insulin and glucagon in the presence of somatostatin infusion was associated with sustained basal glucose production. A selective 4-fold rise in glucagon resulted in an increment in glucose production of approximately $4.5 \mathrm{mg} / \mathrm{kg} / \mathrm{min}$ at 30 minutes. In contrast, a selective 4-fold rise in insulin resulted in a decrement in glucose production of approximately $1.3 \mathrm{mg} / \mathrm{kg} / \mathrm{min}$ at 30 minutes. When both hormones were simultaneously increased 4-fold, the decrement in glucose production at 30 minutes was only approximately $0.6 \mathrm{mg} / \mathrm{kg} / \mathrm{min}$. Therefore, glucagon's effect was $4.5 \mathrm{mg} / \mathrm{kg} / \mathrm{min}$ in the presence of basal insulin - despite the accompanying hyperglycemia - and only $0.7 \mathrm{mg} / \mathrm{kg} / \mathrm{min}$ in the presence of high insulin and euglycemia, a reduction of almost $85 \%$. These data indicate that, in the absence of hypoglycemia, insulin dominates glucagon's action on the liver even when equimolar increments in the 2 hormones are bought about (3). In another previous study

Conflict of interest: The authors have declared that no conflict of interest exists. Citation for this article: J Clin Invest. 2010;120(12):4425-4435. doi:10.1172/JCI40919. from our laboratory (4), a physiologic rise in glucagon significantly increased glucose production $(4.5 \mathrm{mg} / \mathrm{kg} / \mathrm{min}$ increase) in the presence of hypoglycemia, despite an arterial insulin level that was increased 40 -fold ( $328 \mu \mathrm{U} / \mathrm{ml}$ increase). This suggests that under hypoglycemic conditions, glucagon must be able to overcome insulin's potent inhibitory effect on the liver, an action that would appear critical to its role in glucose counterregulation.

To our knowledge, a direct comparison of the ability of a controlled rise in glucagon to overcome insulin's inhibitory effect on glucose production in the presence of euglycemia versus hypoglycemia has never been carried out. Therefore, the first aim of the present study was to determine the extent to which glucagon's ability to overcome the inhibitory effect of insulin on glucose production is enhanced by hypoglycemia. The second aim was to shed light on the cellular mechanisms by which this effect comes about.

\section{Results}

We studied 4 groups of 18-hour fasted conscious dogs: saline-euglycemic (SE), saline-hypoglycemic (SH), glucagon-euglycemic (GE), and glucagon-hypoglycemic (GH). Each experiment consisted of an equilibration period ( -140 to -40 minutes), a basal control period ( -40 to 0 minutes), experimental period 1 ( 0 to 60 minutes), and experimental period 2 (60 to 180 minutes). See Methods for details.

Hormone concentrations. Hepatic sinusoidal insulin rose from baseline to approximately $450 \mu \mathrm{U} / \mathrm{ml}$ in response to insulin infusion (Figure 1A). Hepatic sinusoidal glucagon levels were similar in all groups during the control period $(48 \pm 2 \mathrm{pg} / \mathrm{ml})$ and experimental period 1 , although they fell to approximately $32 \pm 2 \mathrm{pg} / \mathrm{ml}$ during the latter as a result of somatostatin infusion (Figure 1B). These levels remained low in experimental period 2 in the saline-infused groups (SE, $24 \pm 5 \mathrm{pg} / \mathrm{ml}$; SH, $26 \pm 5 \mathrm{pg} / \mathrm{ml}$; last 30 minutes), but rose to $174 \pm 22$ and $175 \pm 15 \mathrm{pg} / \mathrm{ml}$ (last 30 minutes) in response to intraportal glucagon infusion in the GE and GH groups, respectively (Figure 1B). Arterial plasma cortisol was approximately $3.3 \pm 0.2 \mu \mathrm{g} / \mathrm{dl}$ in all groups during the control period and experimental period 1 (Figure $2 \mathrm{~A})$. It 
A
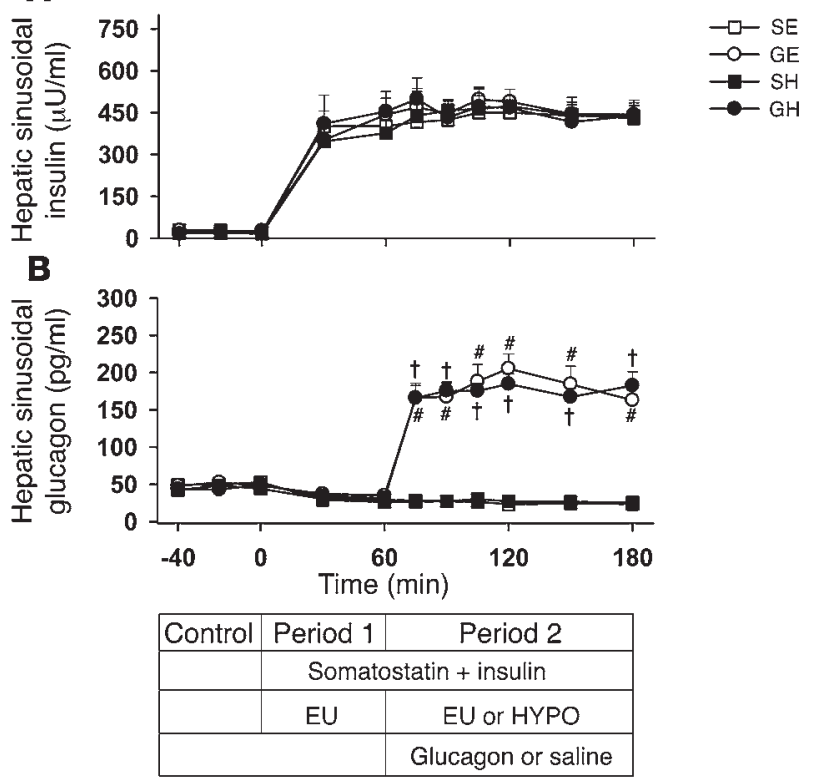

remained low during experimental period 2 in the euglycemic groups (SE, $4.0 \pm 0.9 \mu \mathrm{g} / \mathrm{dl}$; GE, $4.0 \pm 0.8 \mu \mathrm{g} / \mathrm{dl}$; last 30 minutes) but rose to $14 \pm 1$ and $16 \pm 1 \mu \mathrm{g} / \mathrm{dl}$ (last 30 minutes) in response to hypoglycemia in the SH and GH groups, respectively (both $P<0.05$ vs. corresponding euglycemic group). The arterial plasma epinephrine level was basal $(\sim 127 \pm 19 \mathrm{pg} / \mathrm{ml})$ during the control period and experimental period 1 in all groups (Figure $2 \mathrm{~B}$ ). During experimental period 2, it was $101 \pm 29$ and $123 \pm 48 \mathrm{pg} / \mathrm{ml}$ in the $\mathrm{SE}$ and GE groups, but rose to $1,982 \pm 325$ and $1,866 \pm 251 \mathrm{pg} / \mathrm{ml}$ (last 30 minutes) in the SH and GH groups, respectively (both $P<0.05$ vs. corresponding euglycemic group). Likewise, arterial plasma norepinephrine was basal in all groups $(155 \pm 15 \mathrm{pg} / \mathrm{ml})$ during the control period and experimental period 1 (Figure 2C). During experimental period 2, it remained unchanged in the euglycemic groups (SE, $202 \pm 23 \mathrm{pg} / \mathrm{ml}$; GE, $156 \pm 27 \mathrm{pg} / \mathrm{ml}$; last 30 minutes), but increased to $395 \pm 70$ and $346 \pm 57 \mathrm{pg} / \mathrm{ml}$ (last 30 minutes) in the SH and GH groups, respectively (both $P<0.05$ vs. corresponding euglycemic group).

Blood glucose levels and net hepatic glucose balance. Euglycemia was maintained during experimental period 1 in each group and during experimental period 2 in the SE and GE groups (Figure 3A). In the latter groups, glucose infusion rates averaged $16.4 \pm 1.6$ and $14.6 \pm 1.6 \mathrm{mg} / \mathrm{kg} / \mathrm{min}$, respectively, from 60 to $180 \mathrm{~min}$ utes (Table 1). On the other hand, the glucose infusion rates required to maintain hypoglycemia $(49 \mathrm{mg} / \mathrm{dl})$ in the $\mathrm{SH}$ and GH groups were $6.3 \pm 1.2$ and $5.1 \pm 1.6 \mathrm{mg} / \mathrm{kg} / \mathrm{min}$, respectively. Net hepatic glucose output (NHGO) was approximately $1.6 \pm 0.03 \mathrm{mg} / \mathrm{kg} / \mathrm{min}$ in all groups during the control period (Figure $3 \mathrm{~B}$ ). In response to intraportal insulin infusion in the presence of euglycemia and a fall in plasma glucagon, the liver

\section{Figure 2}

Arterial plasma concentrations of counterregulatory hormones. Arterial plasma (A) cortisol, (B) epinephrine, and (C) norepinephrine. Experimental protocols are illustrated as in Figure 1. Values are mean \pm SEM; $n=7$ per group. ${ }^{*} P<0.05$ vs. corresponding euglycemic group; $\dagger P<0.05$, GH vs. SH.

\section{Figure 1}

Hepatic sinusoidal concentrations of pancreatic hormones in 18-hour fasted conscious dogs exposed to a controlled rise of glucagon in the presence of hyperinsulinemia and euglycemia or hypoglycemia. Hepatic sinusoidal (A) insulin and (B) glucagon. Experimental protocols are illustrated below the graphs (see Methods). During experimental period 1, somatostatin $(0.8 \mu \mathrm{g} / \mathrm{kg} / \mathrm{min})$ and intraportal insulin $(5.0 \mathrm{mU} / \mathrm{kg} / \mathrm{min})$ were infused, and euglycemia (EU) was maintained by infusing glucose as required. During experimental period 2, somatostatin and insulin infusions continued and either glucagon $(2.3 \mathrm{ng} / \mathrm{kg} / \mathrm{min})$ or saline $(0.9 \% \mathrm{NaCl})$ was infused intraportally; moreover, glucose was infused as required to maintain euglycemia or establish hypoglycemia (HYPO). Values are mean \pm SEM; $n=7$ per group. ${ }^{\dagger} P<0.05$, $\mathrm{GH}$ vs. $\mathrm{SH} ; " \#<0.05$, GE vs. SE.

switched to slight net hepatic glucose uptake (NHGU) in all groups $(\sim 0.9 \mathrm{mg} / \mathrm{kg} / \mathrm{min}$; Figure $3 \mathrm{~B})$. During experimental period 2, NHGU increased slightly over time (to $1.5 \pm 0.3 \mathrm{mg} / \mathrm{kg} / \mathrm{min}$ ) in the SE group, whereas in the GE group, the liver temporarily switched to NHGO $(\sim 0.3 \pm 0.4 \mathrm{mg} / \mathrm{kg} / \mathrm{min})$ but then reverted to $\mathrm{NHGU}(0.7 \pm 0.4 \mathrm{mg} / \mathrm{kg} / \mathrm{min})$. In the 2 hypoglycemic groups, the liver quickly switched to NHGO and remained in a production mode until the end of the study (SH, $1.2 \pm 0.3 \mathrm{mg} / \mathrm{kg} / \mathrm{min} ; \mathrm{GH}$, $2.9 \pm 0.4 \mathrm{mg} / \mathrm{kg} / \mathrm{min}$; last 30 minutes; $P<0.05)$. The $\triangle \mathrm{AUC}$ for the increase in net hepatic glucose balance (NHGB; 60 to 180 minutes) caused by glucagon was almost 3 -fold greater $(P<0.03)$ in the presence of hypoglycemia (NHGB $\triangle \mathrm{AUC}$ between $\mathrm{SH}$ and GH,

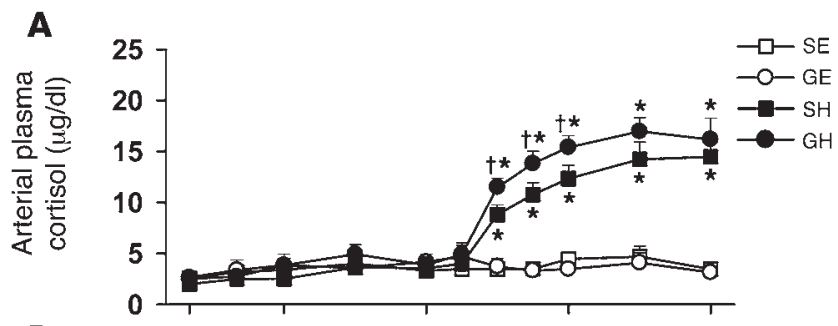

B
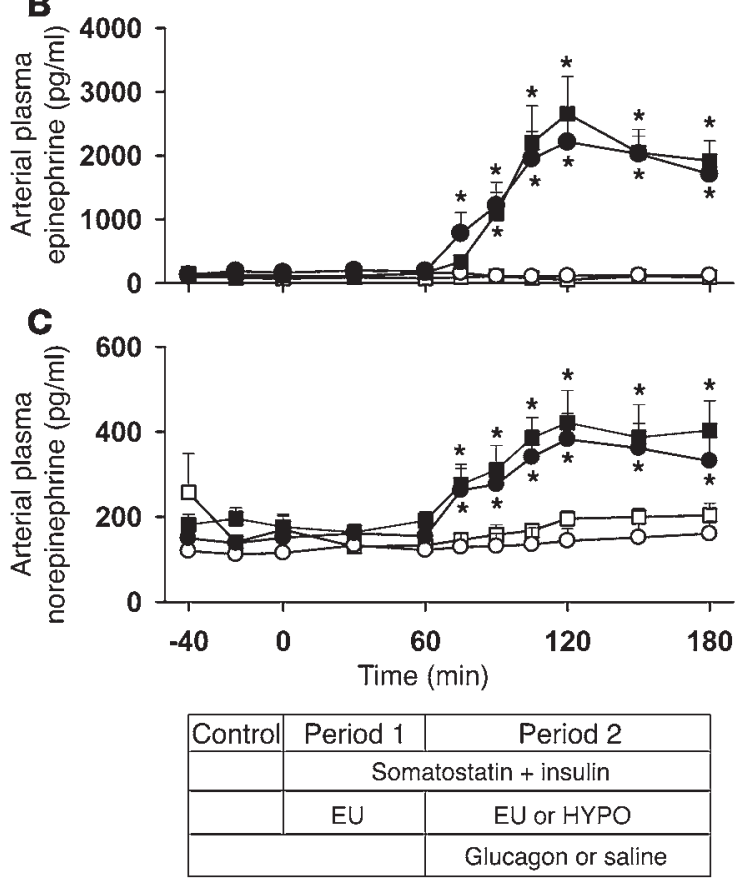


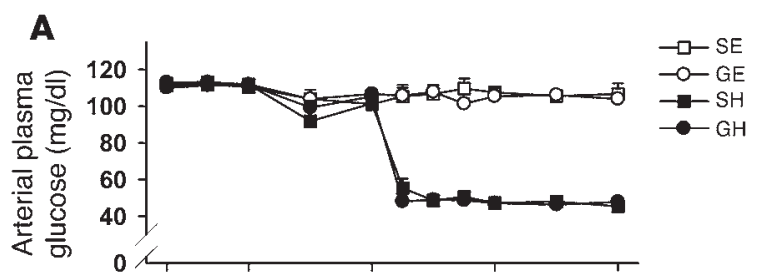

B
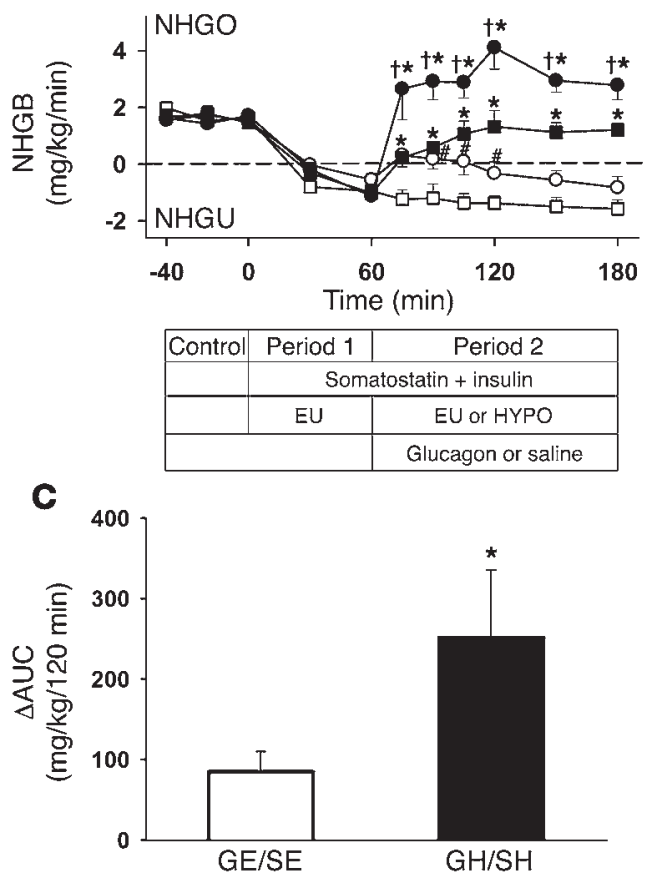

$251 \pm 84 \mathrm{mg} / \mathrm{kg} / 120$ minutes) than in the presence of euglycemia (NHGB $\triangle$ AUC between SE and GE, $85 \pm 25 \mathrm{mg} / \mathrm{kg} / 120$ minutes; Figure $3 \mathrm{C}$ ). Changes in tracer-determined endogenous glucose production paralleled the changes in NHGO (Table 1).

Tracer-determined glucose utilization increased in response to intraportal insulin infusion in all groups during experimental period $1(15.0 \pm 1.5,14.8 \pm 1.1,12.5 \pm 1.2$, and $10.7 \pm 1.2 \mathrm{mg} / \mathrm{kg} / \mathrm{min}$, 60 -minute time point; Table 1). Tracer-determined glucose utilization continued to increase over time in the SE and GE groups (reaching $19.6 \pm 2.2$ and $18.6 \pm 1.3 \mathrm{mg} / \mathrm{kg} / \mathrm{min}$, respectively, by the end of the study), but it decreased in the $\mathrm{SH}$ and $\mathrm{GH}$ groups $(6.2 \pm 0.9$ and $5.3 \pm 0.7 \mathrm{mg} / \mathrm{kg} / \mathrm{min}$, respectively; $P<0.05)$. Glucose clearance increased in all groups during experimental period 1 (Table 1) and rose to a greater extent during experimental period 2 in the euglycemic groups than in the hypoglycemic groups.

Metabolites. Arterial blood alanine levels decreased in response to the rise in insulin in all groups. There was no significant change in net hepatic alanine balance over time and no difference between groups (Table 2). Conversely, fractional extraction of alanine by the liver doubled, although this change did not reach significance in any individual group. Arterial blood lactate levels were basal during the control period and rose slightly in experimental period 1, regardless of group (Table 2). During experimental period 2 , the blood lactate level changed minimally in both euglycemic groups, but increased markedly in response to hypoglycemia with or without glucagon (Table 2). The liver produced lactate during experimental period 1 in all groups. By the end of the study, all

\section{Figure 3}

Blood glucose levels and NHGB. (A) Arterial plasma glucose. (B) NHGB. Experimental protocols are illustrated as in Figure 1. (C) $\triangle A U C$ for the increase in NHGO between 60 and 180 minutes caused by glucagon. Values are mean \pm SEM; $n=7$ per group. ${ }^{*} P<0.05$ vs. corresponding euglycemic group; ${ }^{\dagger} P<0.05$, GH vs. SH; ${ }^{*} P<0.05$, GE vs. SE.

groups had switched to net hepatic lactate uptake, but the hypoglycemic groups were taking up more than 5 times as much lactate as the euglycemic groups. The rise in glucagon was associated with increased net hepatic lactate output for approximately 1 hour under both hypoglycemic and euglycemic conditions. By the end of the study, however, glucagon's presence made no difference with regard to net hepatic lactate balance.

Arterial plasma glycerol levels, which reflect the lipolytic rate, fell in all groups when insulin rose (Table 3 ). They remained suppressed during experimental period 2 in both euglycemic groups, but increased markedly in response to hypoglycemia. Net hepatic glycerol uptake paralleled the changes in the blood glycerol level and was more than 10-fold greater in the presence of hypoglycemia. Glucagon had no effect on glycerol metabolism, regardless of the glycemic condition.

Arterial plasma FFAs and $\beta$-bydroxybutyrate. Arterial plasma FFA levels were basal in all groups during the control period and fell markedly in response to hyperinsulinemia in experimental period 1 (Table 3). During experimental period 2, they fell to less than $50 \mu \mathrm{mol} / \mathrm{l}$ in both euglycemic groups, whereas they increased markedly in the SH and GH groups (to $538 \pm 82$ and $351 \pm 99 \mu \mathrm{mol} / \mathrm{l}$, respectively). Net hepatic FFA uptake paralleled the changes in plasma FFA levels (Table 3 ). Arterial blood $\beta$-hydroxybutyrate (BOHB) levels and net hepatic BOHB output fell in response to the elevation in insulin, but the decline was attenuated in the presence of hypoglycemia with or without glucagon. The presence of glucagon had no discernible effect on FFA or BOHB metabolism (Table 3).

Net hepatic gluconeogenic and glycogenolytic flux. Net hepatic gluconeogenic (NHGNG) flux was approximately $0.0 \pm 0.2 \mathrm{mg} / \mathrm{kg} / \mathrm{min}$ during the control period (Figure $4 \mathrm{~A}$ ) and decreased to approximately $-0.4 \pm 0.1 \mathrm{mg} / \mathrm{kg} / \mathrm{min}$ in all groups during experimental period 1 , indicating net glycolysis. It remained close to 0 in the SE and GE groups during experimental period 2, but increased significantly in response to hypoglycemia ( $\mathrm{SH}$ and $\mathrm{GH}$ ). Since the increase was identical in the 2 hypoglycemic groups $(1.7 \pm 0.4$ and $1.7 \pm 0.3 \mathrm{mg} / \mathrm{kg} / \mathrm{min}$ increases, respectively; $P<0.05)$, the drive for gluconeogenesis was not attributable to glucagon.

Net hepatic glycogenolytic (NHGLY) flux was approximately $1.7 \pm 0.2 \mathrm{mg} / \mathrm{kg} / \mathrm{min}$ in all groups at the end of the control period (Figure 4B). During experimental period 1, NHGLY flux fell to $-0.5 \pm 0.2,-0.7 \pm 0.2,-0.3 \pm 0.3$, and $-0.8 \pm 0.4 \mathrm{mg} / \mathrm{kg} / \mathrm{min}$ in the $\mathrm{SE}, \mathrm{SH}, \mathrm{GE}$, and GH groups, respectively. During experimental period 2, the SE group continued to exhibit net glycogen synthesis $(-1.6 \pm 0.3 \mathrm{mg} / \mathrm{kg} / \mathrm{min})$. Addition of glucagon (GE) caused a small glycogenolytic response followed by a return to net glycogen synthesis, but at a much lower rate than in the SE group. During hypoglycemia in the absence of glucagon (SH), net glycogen synthesis was evident at a very low rate for the entirety of experimental period 2. On the other hand, in the presence of hypoglycemia and an increase in glucagon (GH), NHGLY flux increased to $2.6 \pm 1.0 \mathrm{mg} / \mathrm{kg} / \mathrm{min}$ at 75 minutes and remained elevated throughout the study. The NHGLY flux $\triangle$ AUC between 60 and 180 minutes caused by glucagon was greater in the presence of hypoglycemia $(289 \pm 63 \mathrm{mg} / \mathrm{kg} / 120 \mathrm{~min}$; 


\section{Table 1}

Tracer-determined endogenous glucose production and utilization, glucose clearance, and glucose infusion rate

\begin{tabular}{|c|c|c|c|c|c|c|}
\hline & \multirow[t]{2}{*}{$\begin{array}{l}\text { Control } \\
\text { period }\end{array}$} & \multirow{2}{*}{$\begin{array}{c}\text { Experimental } \\
\text { period } 1 \\
30-60 \mathrm{~min}\end{array}$} & \multicolumn{4}{|c|}{$\begin{array}{l}\text { Experimental } \\
\text { period } 2\end{array}$} \\
\hline & & & $75 \mathrm{~min}$ & $90 \mathrm{~min}$ & $120 \mathrm{~min}$ & $180 \mathrm{~min}$ \\
\hline \multicolumn{7}{|c|}{ Tracer-determined glucose production (mg/kg/min) } \\
\hline $\begin{array}{l}\text { SE } \\
\text { GE } \\
\text { SH } \\
\text { GH }\end{array}$ & $\begin{array}{l}2.9 \pm 0.3 \\
2.2 \pm 0.2 \\
2.5 \pm 0.2 \\
2.4 \pm 0.1\end{array}$ & $\begin{array}{l}0.7 \pm 0.5 \\
0.6 \pm 0.9 \\
0.9 \pm 0.8 \\
0.6 \pm 0.9\end{array}$ & $\begin{aligned}-0.7 & \pm 0.9 \\
0.6 & \pm 0.8 \\
-0.6 & \pm 1.4 \\
2.3 & \pm 0.4 \mathrm{~B}\end{aligned}$ & $\begin{aligned}-0.1 & \pm 0.7 \\
-0.5 & \pm 1.2 \\
-0.1 & \pm 0.9 \\
2.0 & \pm 0.5^{A, B}\end{aligned}$ & $\begin{array}{l}0.4 \pm 0.6 \\
0.1 \pm 1.0 \\
1.9 \pm 0.6^{\mathrm{A}} \\
3.5 \pm 0.6^{\mathrm{A}}\end{array}$ & $\begin{array}{l}1.0 \pm 0.3 \\
0.8 \pm 1.0 \\
1.8 \pm 0.6 \\
3.3 \pm 0.5^{A}\end{array}$ \\
\hline \multicolumn{7}{|c|}{ Tracer-determined glucose utilization (mg/kg/min) } \\
\hline $\begin{array}{l}\text { SE } \\
\text { GE } \\
\text { SH } \\
\text { GH }\end{array}$ & $\begin{array}{l}2.8 \pm 0.3 \\
2.2 \pm 0.2 \\
2.5 \pm 0.2 \\
2.4 \pm 0.2\end{array}$ & $\begin{array}{r}11.9 \pm 1.8 \\
11.6 \pm 1.7 \\
10.6 \pm 1.3 \\
9.2 \pm 1.7\end{array}$ & $\begin{array}{r}15.0 \pm 1.8 \\
13.2 \pm 0.5 \\
8.2 \pm 1.5^{\mathrm{A}} \\
8.1 \pm 1.1^{\mathrm{A}}\end{array}$ & $\begin{aligned} 16.5 & \pm 1.9 \\
14.2 & \pm 0.6 \\
7.3 & \pm 1.1^{\mathrm{A}} \\
7.0 & \pm 1.0^{\mathrm{A}}\end{aligned}$ & $\begin{array}{c}18.2 \pm 2.0 \\
15.8 \pm 0.8 \\
6.3 \pm 0.8^{A} \\
5.8 \pm 0.9^{A}\end{array}$ & $\begin{array}{c}19.6 \pm 2.2 \\
18.6 \pm 1.3 \\
6.2 \pm 0.9^{\mathrm{A}} \\
5.3 \pm 0.7^{\mathrm{A}}\end{array}$ \\
\hline \multicolumn{7}{|c|}{ Glucose clearance (ml/kg/min) } \\
\hline $\begin{array}{l}\text { SE } \\
\text { GE } \\
\text { SH } \\
\text { GH }\end{array}$ & $\begin{array}{l}2.5 \pm 0.3 \\
2.0 \pm 0.2 \\
2.2 \pm 0.2 \\
2.2 \pm 0.1\end{array}$ & $\begin{array}{r}11.4 \pm 1.7 \\
11.1 \pm 1.6 \\
11.0 \pm 1.4 \\
9.3 \pm 1.8\end{array}$ & $\begin{array}{l}14.2 \pm 1.8 \\
12.7 \pm 0.7 \\
12.7 \pm 2.0 \\
13.1 \pm 2.0\end{array}$ & $\begin{array}{l}15.4 \pm 1.7 \\
13.9 \pm 0.9 \\
13.1 \pm 1.9 \\
13.2 \pm 2.0\end{array}$ & $\begin{array}{l}16.8 \pm 1.8 \\
15.7 \pm 1.3 \\
13.4 \pm 1.6 \\
12.6 \pm 2.0\end{array}$ & $\begin{array}{l}18.3 \pm 2.3 \\
18.2 \pm 1.2 \\
13.6 \pm 1.8^{\mathrm{A}} \\
11.8 \pm 1.6^{\mathrm{A}}\end{array}$ \\
\hline \multicolumn{7}{|c|}{ Glucose infusion rate (mg/kg/min) } \\
\hline $\begin{array}{l}\text { SE } \\
\text { GE } \\
\text { SH } \\
\text { GH }\end{array}$ & $\begin{array}{l}\text { NA } \\
N A \\
N A \\
N A\end{array}$ & $\begin{array}{l}6.6 \pm 1.7 \\
6.4 \pm 1.6 \\
6.7 \pm 1.8 \\
7.1 \pm 2.2\end{array}$ & $\begin{array}{r}14.7 \pm 1.1 \\
12.5 \pm 1.4 \\
8.8 \pm 1.0^{\mathrm{A}} \\
7.3 \pm 1.3^{\mathrm{A}}\end{array}$ & $\begin{aligned} 16.4 & \pm 1.5 \\
14.8 & \pm 0.9 \\
5.7 & \pm 0.7^{A} \\
4.0 & \pm 0.9^{A}\end{aligned}$ & $\begin{array}{c}18.4 \pm 1.0 \\
15.0 \pm 1.7 \\
4.5 \pm 0.6^{\mathrm{A}, \mathrm{C}} \\
3.3 \pm 1.0^{\mathrm{A}}\end{array}$ & $\begin{array}{r}18.5 \pm 1.1 \\
18.0 \pm 1.6 \\
4.6 \pm 0.6^{A} \\
3.1 \pm 0.9^{A}\end{array}$ \\
\hline
\end{tabular}

Values are mean $\pm \mathrm{SEM} ; n=7$ per group. ${ }^{\mathrm{A} P}<0.05$ vs. corresponding euglycemic group. ${ }^{\mathrm{B}} P<0.05$ vs. $\mathrm{SH}$.

$P<0.01)$ than in the presence of euglycemia $(127 \pm 20 \mathrm{mg} / \mathrm{kg} / 120 \mathrm{~min}$; $P<0.05)$. Hypoglycemia thus caused a 2.3 -fold increase in the glycogenolytic response to glucagon (Figure 4C).

Molecular changes. Molecular indices in hepatic biopsies from 3-4 dogs in each group were compared with those in hepatic biopsies taken from 3 control animals (overnight-fasted dogs in which somatostatin was given and the levels of insulin, glucagon, and glucose were maintained at basal values). The latter animals were part of another study (5) and are included here for reference purposes only. Levels of phosphorylated Akt (Ser473), GSK3 $\beta$ (Ser9), and glycogen synthase (GS) (Ser641) were assayed as indices of hepatic insulin signaling and glycogen metabolism (Figure 5 and Supplemental Figure 1; supplemental material available online with this article; doi:10.1172/ JCI40919DS1). Animals in the SE and GE groups exhibited similar, marked increases ( $\sim 5$-fold) in P-Akt and P-GSK3 $\beta$, and similar decreases (42\% and 59\%) in P-GS (Ser641), relative to the basal control animals (Figure 5, A-C). However, the presence of hypoglycemia with or without glucagon ( $\mathrm{SH}$ and $\mathrm{GH}$ ) blunted Akt and GSK3 $\beta$ phosphorylation and prevented insulin-mediated Ser641 dephosphorylation (and activation) of GS (Figure 5C). The GS activity ratio increased 4-fold in the SE group, but this activity was lessened by either glucagon (GE) or hypoglycemia $(\mathrm{SH})$ treatment and was further suppressed by the combination of the 2 stimuli (GH; Figure 5D). On the other hand, the glycogen phosphorylase (GP) activity ratio was suppressed ( $\sim 50 \%)$ in SE animals, but this suppression was largely negated in both GE and SH groups (Figure 5E). The combination of glucagon and hypoglycemia (GH) led to a marked 3-fold elevation of GP activity relative to SE. When the activity ratios of the glycogen-metabolizing enzymes were themselves expressed as a ratio (i.e., GP/GS), levels were $15 \%, 85 \%, 40 \%$, and $200 \%$ of basal in the SE, GE, SH, and GH groups, respectively (Figure $5 \mathrm{~F}$ ).

To assess markers of glucagon action and the gluconeogenic program, we assayed levels of phosphorylated CREB (Ser133), FOXO1 (Ser256), CRTC2 (Ser171), and STAT3 (Tyr705) as well as protein levels of PCK and PGC1 $\alpha$ and mRNA levels of G6PC and PCK1 (Figure 6, A-F, and Supplemental Figure 2). P-CREB was reduced by $65 \%$ in the presence of increased insulin, decreased glucagon, and euglycemia, but this decrease was markedly reduced in the presence of glucagon, hypoglycemia, and both combined (GE, SH, and GH; Figure 6A). FOXO1 phosphorylation was markedly increased (4.4-fold) in the SE group relative to control animals, but only a 1.6-fold rise was observed when glucagon was elevated in the absence of hypoglycemia. Furthermore, the effect of insulin on FOXO1 phosphorylation was completely prevented in both hypoglycemic groups (Figure 6B). Phosphorylation of CRTC2 and STAT3 was increased approximately 2-fold in all groups compared with basal control animals (Figure 6, $\mathrm{C}$ and D). Analysis of gene transcription revealed that PCK1 and G6PC mRNA levels were decreased by $84 \%$ and $86 \%$, respectively, in the SE group. This strong repression was modestly lessened by increased glucagon or hypoglycemia, as well as both in combination, but interestingly, transcription remained markedly suppressed relative to that in basal control animals (Figure 6E). PGC1 $\alpha$ and PCK protein levels were reduced by $55 \%$ and $41 \%$, respectively, in the hyperinsulinemic euglycemic group. Their levels failed to change significantly from basal in the presence of glucagon, hypoglycemia, or both combined (Figure 6F), presumably because there was less of a fall in gene expression and there was only a limited time for alteration in mRNA to bring about changes in protein levels. 
Table 2

Lactate and alanine arterial blood levels and net hepatic balance

\begin{tabular}{|c|c|c|c|c|c|c|}
\hline & \multirow[t]{2}{*}{$\begin{array}{l}\text { Control } \\
\text { period }\end{array}$} & \multirow{2}{*}{$\begin{array}{c}\text { Experimental } \\
\text { period } 1 \\
30-60 \mathrm{~min}\end{array}$} & \multicolumn{4}{|c|}{$\begin{array}{l}\text { Experimental } \\
\text { period } 2\end{array}$} \\
\hline & & & $75 \mathrm{~min}$ & $90 \mathrm{~min}$ & $120 \mathrm{~min}$ & $180 \mathrm{~min}$ \\
\hline \multicolumn{7}{|c|}{ Arterial lactate blood level $(\mu \mathrm{mol} / \mathrm{ml})$} \\
\hline $\begin{array}{l}\text { SE } \\
\text { GE } \\
\text { SH } \\
\text { GH }\end{array}$ & $\begin{array}{l}722 \pm 109 \\
552 \pm 119 \\
773 \pm 137 \\
600 \pm 106\end{array}$ & $\begin{array}{l}817 \pm 66 \\
688 \pm 67 \\
845 \pm 82 \\
662 \pm 89\end{array}$ & $\begin{array}{l}763 \pm 101 \\
748 \pm 86 \\
591 \pm 83 \\
632 \pm 102\end{array}$ & $\begin{array}{l}764 \pm 92 \\
791 \pm 77 \\
524 \pm 95 \\
787 \pm 214\end{array}$ & $\begin{array}{c}701 \pm 89 \\
766 \pm 80 \\
1200 \pm 337 \\
1279 \pm 347\end{array}$ & $\begin{array}{c}651 \pm 85 \\
768 \pm 79 \\
1532 \pm 369 A \\
1545 \pm 314^{A}\end{array}$ \\
\hline \multicolumn{7}{|c|}{ Net hepatic lactate balance ( $\mu \mathrm{mol} / \mathrm{kg} / \mathrm{min})$} \\
\hline $\begin{array}{l}\text { SE } \\
\text { GE } \\
\text { SH } \\
\text { GH }\end{array}$ & $\begin{array}{l}8.6 \pm 6.4 \\
1.4 \pm 2.9 \\
6.2 \pm 2.9 \\
3.0 \pm 3.2\end{array}$ & $\begin{array}{r}10 \pm 2.9 \\
7.3 \pm 2.3 \\
10 \pm 2.6 \\
8.6 \pm 1.9\end{array}$ & $\begin{array}{l}5.4 \pm 2.9 \\
6.5 \pm 1.8 \\
0.6 \pm 1.9 \\
5.8 \pm 2.3\end{array}$ & $\begin{array}{r}2.6 \pm 2.6 \\
5.3 \pm 1.8 \\
-4.1 \pm 1.6 \\
3.1 \pm 3.0\end{array}$ & $\begin{array}{r}0.0 \pm 2.6 \\
2.3 \pm 1.4 \\
-9.3 \pm 2.6 \\
-4.0 \pm 2.6\end{array}$ & $\begin{array}{r}-1.9 \pm 1.4 \\
-1.2 \pm 2.8 \\
-11.3 \pm 3.0^{\mathrm{A}} \\
-11.9 \pm 3.6^{\mathrm{A}}\end{array}$ \\
\hline \multicolumn{7}{|c|}{ Lactate fractional extraction } \\
\hline $\begin{array}{l}\text { SE } \\
\text { GE } \\
\text { SH } \\
\text { GH }\end{array}$ & $\begin{array}{l}0.3 \pm 0.27 \\
0.1 \pm 0.16 \\
0.2 \pm 0.01 \\
0.0 \pm 0.14\end{array}$ & $\begin{array}{l}0.6 \pm 0.16 \\
0.5 \pm 0.14 \\
0.5 \pm 0.12 \\
0.5 \pm 0.11\end{array}$ & $\begin{array}{l}0.3 \pm 0.19 \\
0.3 \pm 0.06 \\
0.1 \pm 0.14 \\
0.4 \pm 0.21\end{array}$ & $\begin{aligned} 0.2 & \pm 0.17 \\
0.2 & \pm 0.06 \\
-0.3 & \pm 0.15^{\mathrm{A}} \\
0.2 & \pm 0.16^{\mathrm{B}}\end{aligned}$ & $\begin{array}{r}0.04 \pm 0.14 \\
0.1 \pm 0.08 \\
-0.3 \pm 0.11 \\
-0.1 \pm 0.09\end{array}$ & $\begin{array}{r}-0.1 \pm 0.10 \\
0.0 \pm 0.10 \\
-0.2 \pm 0.06 \\
-0.2 \pm 0.06\end{array}$ \\
\hline \multicolumn{7}{|c|}{ Arterial alanine blood level $(\mu \mathrm{mol} / \mathrm{ml})$} \\
\hline $\begin{array}{l}\text { SE } \\
\text { GE } \\
\text { SH } \\
\text { GH }\end{array}$ & $\begin{array}{l}401 \pm 31 \\
323 \pm 36 \\
381 \pm 36 \\
353 \pm 52\end{array}$ & $\begin{array}{l}336 \pm 34 \\
267 \pm 27 \\
319 \pm 36 \\
344 \pm 39\end{array}$ & $\begin{array}{l}259 \pm 15 \\
215 \pm 20 \\
237 \pm 23 \\
234 \pm 22\end{array}$ & $\begin{array}{l}223 \pm 13 \\
207 \pm 24 \\
204 \pm 15 \\
206 \pm 19\end{array}$ & $\begin{array}{l}191 \pm 12 \\
182 \pm 19 \\
188 \pm 15 \\
192 \pm 20\end{array}$ & $\begin{array}{l}151 \pm 12 \\
151 \pm 15 \\
168 \pm 12 \\
164 \pm 18\end{array}$ \\
\hline \multicolumn{7}{|c|}{ Net hepatic alanine balance ( $\mu \mathrm{mol} / \mathrm{kg} / \mathrm{min})$} \\
\hline $\begin{array}{l}\text { SE } \\
\text { GE } \\
\text { SH } \\
\text { GH }\end{array}$ & $\begin{array}{l}-2.3 \pm 0.3 \\
-2.3 \pm 0.3 \\
-2.3 \pm 0.4 \\
-2.6 \pm 0.5\end{array}$ & $\begin{array}{l}-2.6 \pm 0.2 \\
-2.3 \pm 0.4 \\
-2.3 \pm 0.5 \\
-2.2 \pm 0.3\end{array}$ & $\begin{array}{l}-2.6 \pm 0.5 \\
-2.4 \pm 0.3 \\
-2.1 \pm 0.4 \\
-2.8 \pm 0.4\end{array}$ & $\begin{array}{l}-2.3 \pm 0.4 \\
-2.2 \pm 0.3 \\
-2.2 \pm 0.2 \\
-2.2 \pm 0.3\end{array}$ & $\begin{array}{l}-2.6 \pm 0.2 \\
-2.3 \pm 0.3 \\
-2.2 \pm 0.3 \\
-2.3 \pm 0.4\end{array}$ & $\begin{array}{l}-2.3 \pm 0.2 \\
-2.4 \pm 0.4 \\
-2.8 \pm 0.3 \\
-2.9 \pm 0.4\end{array}$ \\
\hline \multicolumn{7}{|c|}{ Alanine fractional extraction } \\
\hline $\begin{array}{l}\text { SE } \\
\text { GE } \\
\text { SH } \\
\text { GH }\end{array}$ & $\begin{array}{l}-0.2 \pm 0.03 \\
-0.2 \pm 0.02 \\
-0.2 \pm 0.03 \\
-0.2 \pm 0.05\end{array}$ & $\begin{array}{l}-0.3 \pm 0.02 \\
-0.3 \pm 0.02 \\
-0.3 \pm 0.05 \\
-0.3 \pm 0.06\end{array}$ & $\begin{array}{l}-0.3 \pm 0.05 \\
-0.3 \pm 0.02 \\
-0.3 \pm 0.04 \\
-0.4 \pm 0.04\end{array}$ & $\begin{array}{l}-0.4 \pm 0.05 \\
-0.3 \pm 0.02 \\
-0.3 \pm 0.03 \\
-0.3 \pm 0.05\end{array}$ & $\begin{array}{l}-0.4 \pm 0.04 \\
-0.4 \pm 0.03 \\
-0.3 \pm 0.04 \\
-0.3 \pm 0.05\end{array}$ & $\begin{array}{l}-0.5 \pm 0.02 \\
-0.4 \pm 0.03 \\
-0.4 \pm 0.03 \\
-0.4 \pm 0.05\end{array}$ \\
\hline
\end{tabular}

Values are mean \pm SEM; $n=7$ per group. ${ }^{A} P<0.05$ vs. corresponding euglycemic group. ${ }^{B} P<0.05$ vs. SH. Negative balance is indicative of uptake.

AMPK phosphorylation at the Thr172 site did not change in the SE animals. On the other hand, both glucagon and hypoglycemia (GE and $\mathrm{SH}$ ) caused a 2.5 -fold increase in P-AMPK, and the combination (GH) led to a nearly 4-fold rise (Figure 7A). AMPK phosphorylation at Ser485 was 2.5-fold higher in the SE group than in basal control animals. This increase was prevented by glucagon, hypoglycemia, or the combination (Figure 7B). Finally, P-ACC1, a downstream marker of AMPK activity, confirmed the results obtained with AMPK at the Thr172 site (Figure 7C).

\section{Discussion}

Previous studies have shown that the $\alpha$ cell is critical for a normal counterregulatory response to insulin-induced hypoglycemia $(4,6-9)$. In fact, glucagon is widely thought to provide the primary defense against a low blood glucose level. On the other hand, insulin is known to exert a powerful restraining effect on glucagon's action (3). This raises the question of how glucagon can have such a prominent role in counterregulation if it is so easily subject to insulin's inhibitory action. The aim of the present study, therefore, was to determine the extent to which hypoglycemia enhances glucagon's ability to overcome insulin's inhibitory action on the liver and to shed light on the mechanism by which this occurs. The present results indicate that hypoglycemia $(\sim 50 \mathrm{mg} / \mathrm{dl})$, or some factor associated with it, enhanced glucagon's ability to increase glucose production almost 3-fold, even in the presence of extremely high insulin levels. Furthermore, they showed that this change reflected a marked increase in glycogenolysis, which was associated with hypoglycemia-induced inhibition of insulin signaling and increased AMPK activity caused by the combined effects of the fall in glucose and the rise in glucagon.

In the current study, in the presence of hyperinsulinemia and euglycemia, a physiologic rise in glucagon mimicking that occurs in response to insulin-induced hypoglycemia, caused an increase in $\mathrm{NHGO}$ that had a $\triangle \mathrm{AUC}$ of $85 \mathrm{mg} / \mathrm{kg} / 120 \mathrm{~min}$. When the same rise in glucagon was brought about under hypoglycemic conditions, it produced a 3 -fold greater increase $(251 \mathrm{mg} / \mathrm{kg} / 120 \mathrm{~min})$ in NHGO. This correlated with a 2.3-fold greater increase in glycogenolysis and little or no difference in gluconeogenesis. It should be noted that the changes in plasma epinephrine, norepinephrine, and cortisol that occurred in response to hypoglycemia were the same whether gluca- 
Table 3

Arterial plasma FFA levels, glycerol and BOHB blood levels, and net hepatic balance

\begin{tabular}{|c|c|c|c|c|c|c|}
\hline & \multirow[t]{2}{*}{$\begin{array}{l}\text { Control } \\
\text { period }\end{array}$} & \multirow{2}{*}{$\begin{array}{c}\text { Experimental } \\
\text { period } 1 \\
30-60 \mathrm{~min}\end{array}$} & \multicolumn{4}{|c|}{$\begin{array}{l}\text { Experimental } \\
\text { period } 2\end{array}$} \\
\hline & & & $75 \mathrm{~min}$ & $90 \mathrm{~min}$ & $120 \mathrm{~min}$ & $180 \mathrm{~min}$ \\
\hline \multicolumn{7}{|c|}{ Arterial plasma FFA level ( $\mu \mathrm{mol} / \mathrm{l})$} \\
\hline $\begin{array}{l}\text { SE } \\
\text { GE } \\
\text { SH } \\
\text { GH }\end{array}$ & $\begin{array}{l}756 \pm 124 \\
840 \pm 109 \\
816 \pm 79 \\
829 \pm 112\end{array}$ & $\begin{array}{r}124 \pm 23 \\
109 \pm 22 \\
120 \pm 15 \\
95 \pm 28\end{array}$ & $\begin{aligned} 79 & \pm 9 \\
91 & \pm 21 \\
233 & \pm 132 \\
155 & \pm 44\end{aligned}$ & $\begin{array}{c}66 \pm 6 \\
67 \pm 16 \\
587 \pm 162^{A} \\
267 \pm 50^{B}\end{array}$ & $\begin{array}{c}54 \pm 6 \\
49 \pm 13 \\
607 \pm 112^{A} \\
535 \pm 137^{A}\end{array}$ & $\begin{array}{c}38 \pm 5 \\
43 \pm 11 \\
513 \pm 73^{A} \\
338 \pm 105^{A}\end{array}$ \\
\hline \multicolumn{7}{|c|}{ Net hepatic FFA balance ( $\mu \mathrm{mol} / \mathrm{kg} / \mathrm{min})$} \\
\hline $\begin{array}{l}\text { SE } \\
\text { GE } \\
\text { SH } \\
\text { GH }\end{array}$ & $\begin{array}{l}-2.8 \pm 0.6 \\
-2.9 \pm 0.4 \\
-2.7 \pm 0.4 \\
-3.0 \pm 0.6\end{array}$ & $\begin{array}{r}-0.1 \pm 0.2 \\
-0.2 \pm 0.1 \\
0.0 \pm 0.1 \\
0.0 \pm 0.1\end{array}$ & $\begin{array}{r}0.0 \pm 0.1 \\
-0.2 \pm 0.1 \\
-0.6 \pm 0.5 \\
-0.2 \pm 0.2\end{array}$ & $\begin{aligned} 0.0 & \pm 0.1 \\
-0.2 & \pm 0.1 \\
-2.2 & \pm 0.7^{\mathrm{A}} \\
-0.6 & \pm 0.2^{\mathrm{B}}\end{aligned}$ & $\begin{aligned}-0.1 & \pm 0.1 \\
0.0 & \pm 0.1 \\
-2.6 & \pm 0.5^{A} \\
-1.8 & \pm 0.7^{A}\end{aligned}$ & $\begin{array}{l}0.0 \pm 0.1 \\
-0.1 \pm 0.1 \\
-2.0 \pm 0.5^{\mathrm{A}} \\
-1.2 \pm 0.6\end{array}$ \\
\hline \multicolumn{7}{|c|}{ Arterial glycerol blood level ( $\mu \mathrm{mol} / \mathrm{ml})$} \\
\hline $\begin{array}{l}\text { SE } \\
\text { GE } \\
\text { SH } \\
\text { GH }\end{array}$ & $\begin{array}{l}78 \pm 17 \\
86 \pm 15 \\
80 \pm 10 \\
85 \pm 15\end{array}$ & $\begin{array}{l}33 \pm 12 \\
38 \pm 11 \\
38 \pm 8 \\
42 \pm 13\end{array}$ & $\begin{array}{c}26 \pm 6 \\
26 \pm 6 \\
73 \pm 29 \\
104 \pm 45^{A}\end{array}$ & $\begin{array}{c}24 \pm 8 \\
28 \pm 7 \\
163 \pm 26^{A} \\
125 \pm 27^{A}\end{array}$ & $\begin{array}{c}22 \pm 8 \\
22 \pm 4 \\
235 \pm 35^{A} \\
212 \pm 26^{A}\end{array}$ & $\begin{array}{c}22 \pm 5 \\
28 \pm 6 \\
257 \pm 36^{\mathrm{A}} \\
199 \pm 27^{\mathrm{A}, \mathrm{B}}\end{array}$ \\
\hline \multicolumn{7}{|c|}{ Net hepatic glycerol balance ( $\mu \mathrm{mol} / \mathrm{kg} / \mathrm{min})$} \\
\hline $\begin{array}{l}\text { SE } \\
\text { GE } \\
\text { SH } \\
\text { GH }\end{array}$ & $\begin{array}{l}-1.6 \pm 0.4 \\
-1.7 \pm 0.3 \\
-1.7 \pm 0.2 \\
-2.2 \pm 0.5\end{array}$ & $\begin{array}{l}-0.5 \pm 0.2 \\
-0.7 \pm 0.2 \\
-0.8 \pm 0.2 \\
-1.0 \pm 0.4\end{array}$ & $\begin{array}{l}-0.5 \pm 0.1 \\
-0.7 \pm 0.4 \\
-2.0 \pm 1.0 \\
-2.8 \pm 1.0^{\mathrm{A}}\end{array}$ & $\begin{array}{l}-0.4 \pm 0.1 \\
-0.4 \pm 0.2 \\
-3.9 \pm 0.8^{\mathrm{A}} \\
-3.1 \pm 0.5^{\mathrm{A}}\end{array}$ & $\begin{array}{l}-0.4 \pm 0.1 \\
-0.4 \pm 0.1 \\
-5.5 \pm 1.2^{\mathrm{A}} \\
-5.1 \pm 0.7^{\mathrm{A}}\end{array}$ & $\begin{array}{l}-0.5 \pm 0.1 \\
-0.7 \pm 0.2 \\
-7.2 \pm 1.4^{\mathrm{A}} \\
-5.6 \pm 0.6^{\mathrm{A}, \mathrm{B}}\end{array}$ \\
\hline \multicolumn{7}{|c|}{ Arterial BOHB blood level ( $\mu \mathrm{mol} / \mathrm{ml})$} \\
\hline $\begin{array}{l}\text { SE } \\
\text { GE } \\
\text { SH } \\
\text { GH }\end{array}$ & $\begin{array}{l}29 \pm 5 \\
38 \pm 9 \\
28 \pm 3 \\
31 \pm 6\end{array}$ & $\begin{array}{l}21 \pm 4 \\
13 \pm 1 \\
20 \pm 6 \\
14 \pm 1\end{array}$ & $\begin{array}{l}21 \pm 4 \\
10 \pm 1 \\
17 \pm 5 \\
13 \pm 2\end{array}$ & $\begin{array}{l}17 \pm 4 \\
10 \pm 1 \\
30 \pm 5 \\
14 \pm 1^{B}\end{array}$ & $\begin{aligned} 18 & \pm 5 \\
9 & \pm 1 \\
33 & \pm 10 \\
18 & \pm 2\end{aligned}$ & $\begin{array}{l}20 \pm 5 \\
10 \pm 1 \\
30 \pm 12 \\
16 \pm 2\end{array}$ \\
\hline \multicolumn{7}{|c|}{ Net hepatic BOHB balance $(\mu \mathrm{mol} / \mathrm{kg} / \mathrm{min})$} \\
\hline $\begin{array}{l}\text { SE } \\
\text { GE } \\
\text { SH } \\
\text { GH }\end{array}$ & $\begin{array}{l}0.5 \pm 0.1 \\
1.1 \pm 0.3 \\
0.5 \pm 0.2 \\
0.9 \pm 0.3\end{array}$ & $\begin{array}{l}0.2 \pm 0.1 \\
0.2 \pm 0.1 \\
0.3 \pm 0.1 \\
0.2 \pm 0.1\end{array}$ & $\begin{array}{l}0.1 \pm 0.0 \\
0.2 \pm 0.1 \\
0.3 \pm 0.1 \\
0.2 \pm 0.1\end{array}$ & $\begin{array}{l}0.1 \pm 0.0 \\
0.1 \pm 0.1 \\
0.8 \pm 0.4 \\
0.2 \pm 0.1\end{array}$ & $\begin{array}{l}0.0 \pm 0.1 \\
0.1 \pm 0.0 \\
0.3 \pm 0.2 \\
0.3 \pm 0.1\end{array}$ & $\begin{array}{l}0.0 \pm 0.0 \\
0.1 \pm 0.0 \\
0.3 \pm 0.2 \\
0.2 \pm 0.1\end{array}$ \\
\hline
\end{tabular}

Values are mean $\pm \mathrm{SEM} ; n=7$ per group. ${ }^{A} P<0.05$ vs. corresponding euglycemic group. ${ }^{\mathrm{B} P}<0.05$ vs. SH. Negative balance is indicative of uptake.

gon was increased or not; thus, a differential response in their secretion or subsequent effects on the liver cannot explain the difference in glucose production in the 2 hypoglycemic groups.

Although differences in gluconeogenesis were not part of the explanation for the increase in glucagon action, hypoglycemia with or without glucagon (SH and GH) caused a marked $1.7-\mathrm{mg} / \mathrm{kg} / \mathrm{min}$ increase in NHGNG flux. This leads to the question of how the increase in gluconeogenesis came about, since the cellular indices of the gluconeogenic program were either at or below values evident in the control animals. The answer lies in the fact that hypoglycemia caused marked increases in the release of lactate from muscle and glycerol from fat. This resulted in large increments in their delivery to and uptake by the liver, which in turn caused a substrate-driven increase in gluconeogenic flux. The increase in muscle glycogenolysis undoubtedly resulted from the hypoglycemia-driven rise in plasma epinephrine, whereas the increase in lipolysis probably resulted from the hypoglycemia-driven increase in neural input (norepinephrine) to fat $(10,11)$.

The question then arises as to the mechanism by which the liver's glycogenolytic responsiveness to glucagon was enhanced by hypoglycemia. It is unclear which physiologic signal - increased cortisol; increased epinephrine; increased norepinephrine; increased neural input to the liver, fat, and muscle; hypoglycemia per se; or some combination of these - explains this important adaptive response. It is clear that the liver is capable of adjusting its glucose output in response to variations in the blood glucose concentration, independent of hormonal changes (12-16). This phenomenon of hepatic autoregulation has been demonstrated to occur in various in vitro preparations (14-16) and in vivo $(12,13)$. It is therefore possible that hypoglycemia per se sensitized the liver to glucagon.

Another possibility is that the enhanced response of the liver to glucagon during insulin-induced hypoglycemia is related to the interaction of glucagon with one or other of the counterregulatory hormones. Several studies have looked at the acute interaction of the counterregulatory hormones (17-20). Lecavalier et al. (19) performed studies in humans to assess the interaction between glucagon and cortisol on gluconeogenesis from ${ }^{14} \mathrm{C}$ lactate. In their studies, glucose was clamped, and they used a pancreatic pituitary clamp to control for changes in insulin, glucagon, and 

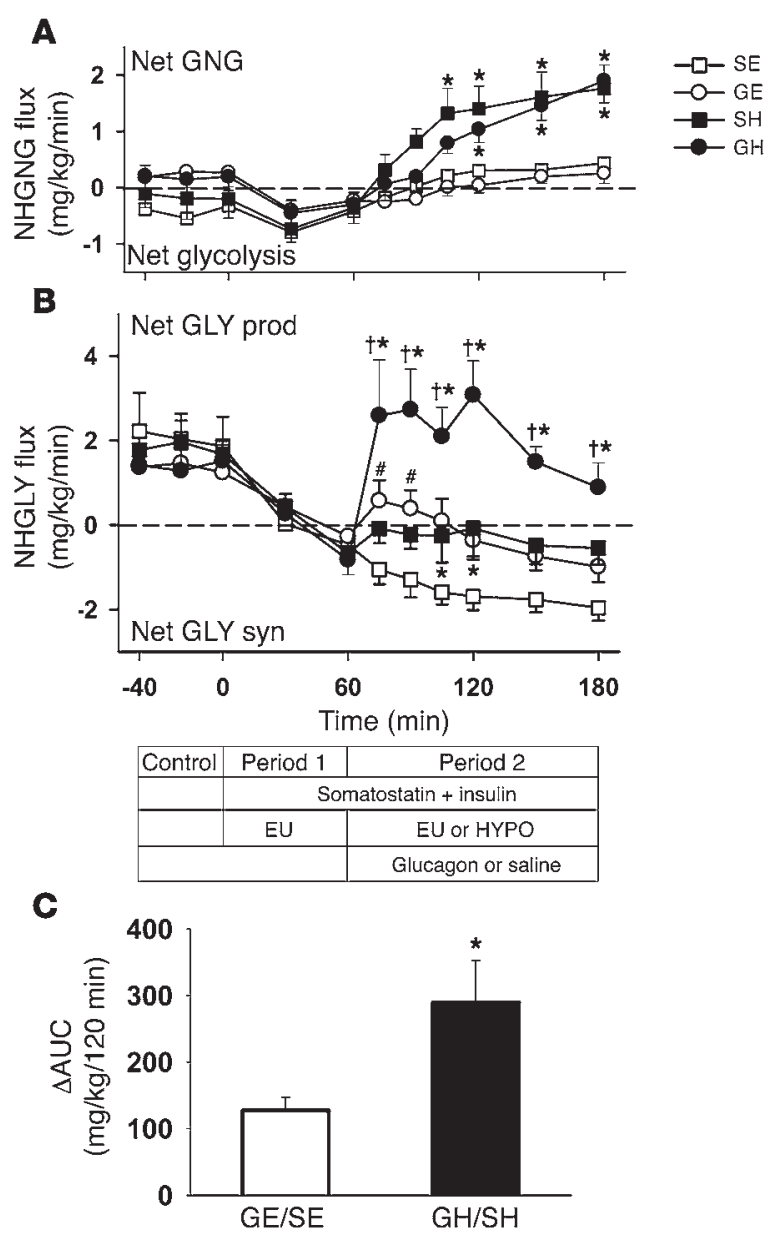

growth hormone. They found that cortisol and glucagon stimulated gluconeogenesis in an additive manner. However, the increment in glucagon that they used was very high, so it is conceivable that a synergistic effect of the hormones could have been missed. Gustavson et al. (20) studied the interaction of epinephrine and glucagon in the regulation of hepatic glucose production at a time when plasma insulin and hyperglycemia were fixed in overnight-fasted conscious dogs. They observed that the effects of glucagon and epinephrine on hepatic glucose production were additive, but not synergistic. Thus, the data currently available do not support a synergistic interaction between glucagon and the other counterregulatory hormones. It must be remembered, however, that none of the above studies were carried out under hypoglycemic conditions. It is possible that the combination of hypoglycemia and the rise in counterregulatory hormones is critical to the enhanced response.

It is also of interest to examine the cellular changes associated with the increased glycogenolytic effect of glucagon. Berglund et al. (21) recently demonstrated that a physiological rise in glucagon or hypoglycemia can activate AMPK in mouse liver. In addition, previous studies have shown that portal infusion of the AMPK activator AICAR stimulated hepatic glucose production (through an increase in glycogenolysis) despite substantial hyperinsulinemia and fixed glucagon levels (22). In light of these data, we evaluated hepatic AMPK activation in the present studies. In the presence of high insulin, low glucagon, and euglycemia, P-AMPK

\section{Figure 4}

NHGNG (A) and NHGLY (B) flux. Net GNG, net gluconeogenetic flux; Net GLY prod, net glycogenolytic flux; Net GLY syn, net glycogenolytic synthesis. Experimental protocols are illustrated as in Figure 1. (C) $\triangle A U C$ for the increase in NHGLY between 60 and 180 minutes caused by glucagon. Values are mean $\pm \mathrm{SEM} ; n=7$ per group. ${ }^{\star} P<0.05$ vs. corresponding euglycemic group; ${ }^{\dagger} P<0.05, \mathrm{GH}$ vs. $\mathrm{SH}$; $\# P<0.05$, GE vs. SE.

(Thr172) was not different from that in control animals. On the other hand, the addition of glucagon (GE) or hypoglycemia (SH) led to a similar increase in AMPK (Thr172) phosphorylation. Furthermore, the combination of glucagon and hypoglycemia had an additive effect on AMPK phosphorylation. Since AMPK activation correlated with NHGLY flux in all groups, one can speculate that AMPK played a key regulatory role in promoting glycogenolysis in response to glucagon and/or hypoglycemia.

It is possible that AMPK regulates glycogen synthase and glycogen phosphorylase within the liver, although to date, this regulation has not been clearly established in vivo. To our knowledge, there is no evidence that AMPK can directly phosphorylate GP. However, a recent in vitro study suggested that AMPK may indirectly reduce PP1-mediated dephosphorylation of GS and GP, the net effect of which would favor glycogenolysis (23). In addition, AMPK can directly phosphorylate GS at Ser7 (24). Furthermore, Ser7 has been shown to be the dominant phosphorylation site responsible for GS inhibition, at least in isolated hepatocytes (25). Unfortunately, we were unable to evaluate GS (Ser7) phosphorylation because of the unavailability of a commercial antibody. However, the alterations (increased GP, decreased GS) observed with either hypoglycemia or glucagon correlated with AMPK activation. That the most marked change in the activity ratios of GP and GS (favoring glycogenolytic flux) occurred with combination of glucagon and hypoglycemia (and the greatest increase in AMPK activation) is consistent with the suggestion that AMPK may be one of the prominent regulators of glycogen metabolism in this context.

It is also of interest to note that AMPK phosphorylation at Ser485 was markedly enhanced by the presence of high insulin (SE). Akt is known to phosphorylate hepatic AMPK at Ser485, which prevents phosphorylation of AMPK at Thr172 and activation of the enzyme (26). Thus, Ser 485 phosphorylation can be considered an index of AMPK inhibition by insulin. Ser485 phosphorylation was reduced equivalently by glucagon and/or hypoglycemia in the present study, whereas previous studies in isolated cells indicated that cAMPelevating agents increased Ser485 phosphorylation of AMPK (27). This discrepancy may be explained, at lease in part, by the fact that the former studies were performed in vitro and thus lacked important inputs for hepatic glucose regulation that were present in our studies. In any case, we believe our data are the first to suggest that AMPK dephosphorylation at Ser485, mediated by either glucagon or hypoglycemia, may be relevant to the ability of the liver to overcome the effects of insulin on glucose production.

In the presence of high insulin, low glucagon, and euglycemia (SE), the insulin signaling pathway was strongly activated (as evidenced by marked increases in phosphorylated Akt and GSK3 $\beta$ and decreased phosphorylation of GS at Ser641), which was correlated with inhibited glycogenolysis and stimulated glycogen synthesis. The addition of glucagon under euglycemic conditions (GE) led to an increase in glycogenolytic flux, despite no attenuation of insulin signaling. When hypoglycemia was allowed 
A

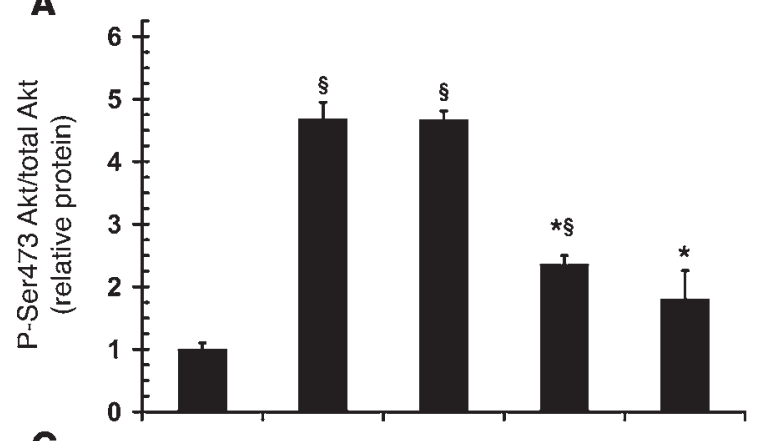

c

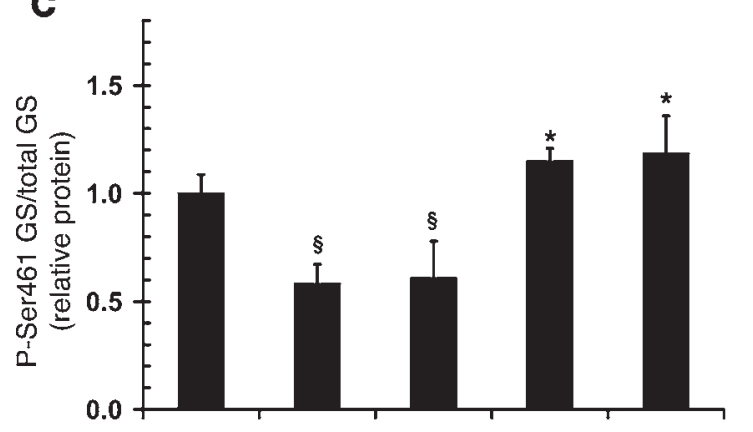

E

E

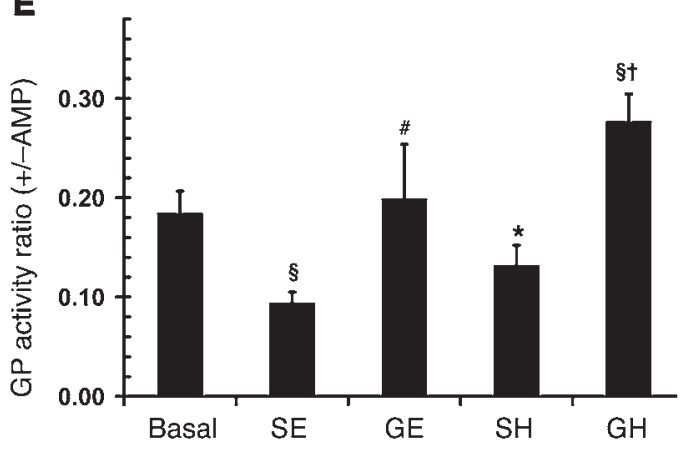

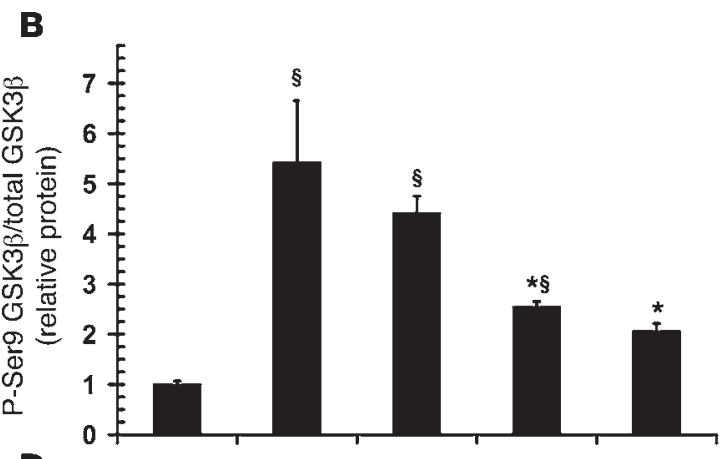

D

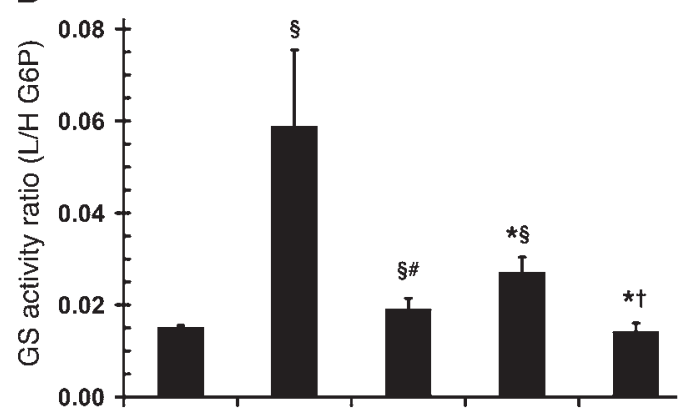

$\mathbf{F}$

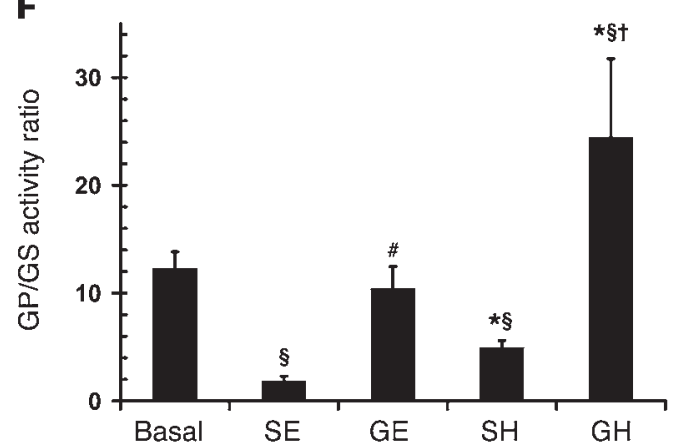

Figure 5

Markers of insulin signaling and glycogen metabolism. Phosphorylation of (A) Akt (Ser473), (B) GSK3 $\beta$ (Ser9), and (C) GS (Ser641) relative to levels observed in basal control animals. Activity ratios of (D) GS, (E) GP, and (F) GP/GS. Values are means \pm SEM; $n=3-4$ per group. $\$ P<0.05$ vs. basal; ${ }^{*} P<0.05$ vs. corresponding euglycemic group; $+P<0.05$, GH vs. SH; $\#<0.05$, GE vs. SE.

to occur in the absence of glucagon $(\mathrm{SH})$, insulin signaling was blunted (decreased phosphorylation of Akt, GSK3 $\beta$, and increased Ser641 phosphorylation of GS), and this resulted in increased glycogenolysis. The addition of glucagon to hypoglycemia (GH) did not cause a further reduction in insulin signaling, yet it caused the greatest increase in the glycogenolytic rate. Thus, our data suggest that hypoglycemia, or some aspect associated with it, can interfere with insulin-mediated regulation of Akt, GSK3 $\beta$, and GS (Ser641), which undoubtedly facilitates hepatic glycogenolysis. Moreover, we posit that the addition of glucagon (which does not impair insulin signaling) stimulated glycogenolysis, possibly through AMPK-mediated alteration of GS and GP activities. Finally, this glycogenolytic effect was magnified when glucagon and hypoglycemia were combined, leading to an additive effect on AMPK activation, in the presence of hypoglycemia-mediated impairment of insulin signaling.

Although gluconeogenic flux was not a major factor in increased glucose production in the acute response to glucagon and/or hypoglycemia, it is interesting to note that the substan- tial suppression of the gluconeogenic program at the genetic level was only modestly lessened by addition of glucagon and/or the hypoglycemic condition. Insulin (SE) predictably led to increased FOXO1, STAT3, and CRTC2 phosphorylation and decreased CREB phosphorylation, all of which likely factored into the substantial decrease observed in gluconeogenic gene expression. Addition of glucagon and/or hypoglycemia (GE, SH, and $\mathrm{GH}$ ) led to slight increases in gluconeogenic mRNA that correlated with alterations in CREB and FOXO1 phosphorylation. However, STAT3 and CRTC2 phosphorylation were maintained at elevated levels, and since gluconeogenic gene expression was still largely suppressed, it appears that these factors may dominate the control of PCK1 and G6PC gene expression, at least during hyperinsulinemia. In addition, AMPK, much like insulin, can phosphorylate CRTC2, resulting in the cytoplasmic sequestration of this protein and a consequent reduction in gluconeogenic gene expression (28). However, our results indicate that the level of CRTC2 phosphorylation in response to insulin (SE) was not further increased in the GE, SH or GH groups despite the activa- 
A

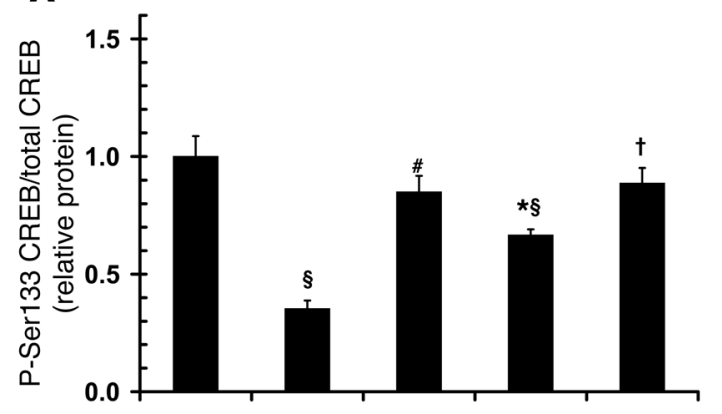

C

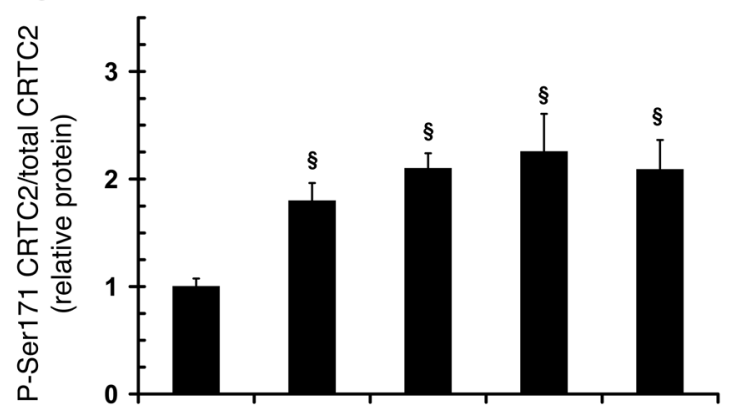

E

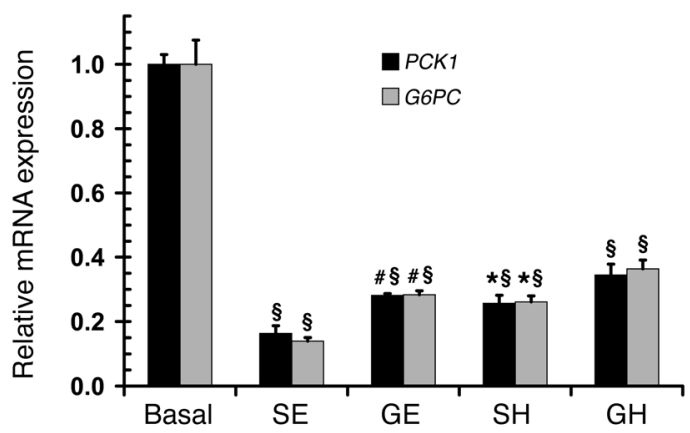

B

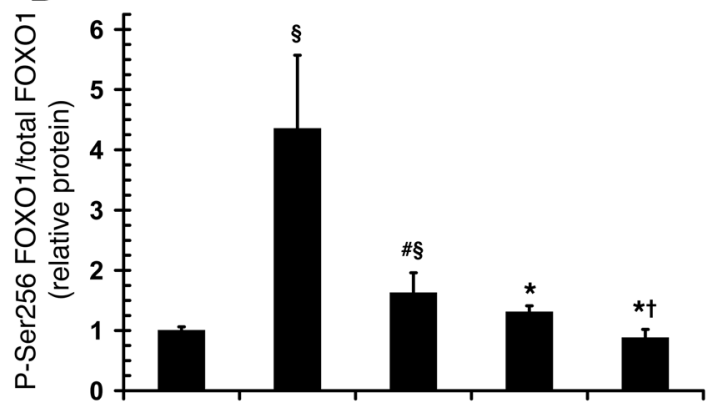

D

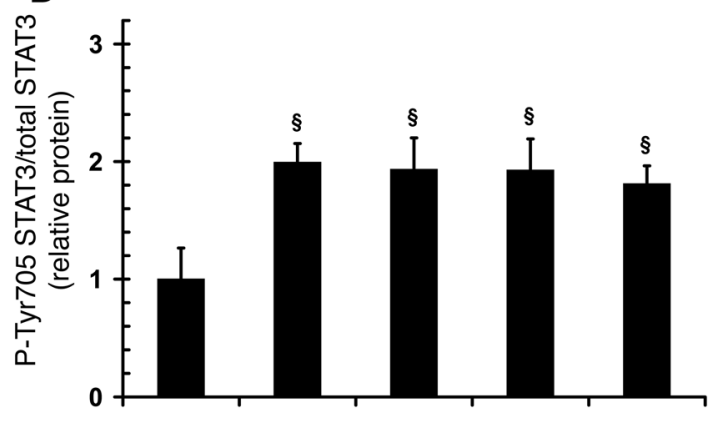

$\mathbf{F}$

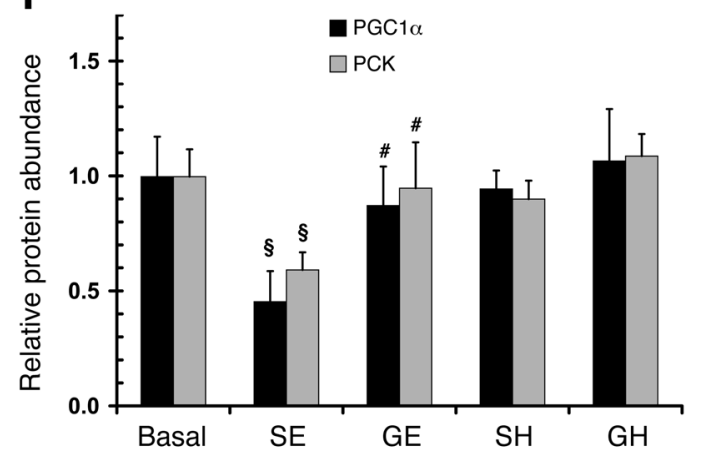

Figure 6

Markers of glucagon action and the gluconeogenic program. Phosphorylation of (A) CREB (Ser133), (B) FOXO1 (Ser256), (C) CRTC2 (Ser171), and (D) STAT3 (Tyr705) and levels of (E) gluconeogenic mRNA (PCK1 and G6PC) and (F) gluconeogenic protein (PCK and PGC1 $\alpha)$ expression, relative to levels observed in basal control animals. Values are mean $\pm \mathrm{SEM} ; n=3-4$ per group. $\$ P<0.05$ vs. basal; ${ }^{\star} P<0.05$ vs. corresponding euglycemic group; ${ }^{\dagger} P<0.05, \mathrm{GH}$ vs. SH; $\# P<0.05$, GE vs. SE.

tion of AMPK. It therefore appears that in the presence of marked hyperinsulinemia, AMPK activation by glucagon and/or hypoglycemia does not cause further CRTC2 phosphorylation.

In summary, hypoglycemia increased glucagon's ability to overcome insulin's inhibitory effect on hepatic glucose production. This effect was attributable to marked enhancement of net glycogen breakdown with no effect on gluconeogenesis. At the cellular level, it was associated with reduced insulin signaling caused by some aspect of hypoglycemia and by activation of AMPK resulting from the combination of increased glucagon and hypoglycemia. Which aspect of hypoglycemia causes these changes (hypoglycemia per se, or some other component of the counterregulatory response) remains to be determined.

\section{Methods}

Animal care and surgical procedures. Experiments were performed on 18-hour overnight-fasted, conscious mongrel dogs of either sex (19-25 kg). The surgical facility met the standards published by the American Associa- tion for the Accreditation of Laboratory Animal Care guidelines, and the protocol was approved by the Vanderbilt University Medical Center Animal Care Committee.

At 2 weeks prior to the study, a laparotomy was performed for placement of silastic catheters in the jejunal and splenic veins for intraportal infusion of insulin (Lilly) and glucagon (Lilly), and sampling catheters in the femoral artery as well as the portal vein and left common hepatic vein, as previously described (29). Ultrasonic flow probes (Transonic Systems) were positioned around the hepatic artery and portal vein, as described previously (30). All the animals studied met the established criteria for good health: (a) leukocyte count less than $18,000 / \mathrm{mm}^{3}$, (b) hematocrit greater than $35 \%$, (c) good appetite, and (d) normal stools. On the day of the study, catheters were placed in leg veins for $\left[3-{ }^{3} \mathrm{H}\right]$ glucose (Du Pont NEN), indocyanine green (Sigma-Aldrich), peripheral glucose (20\% dextrose; Baxter Healthcare), and somatostatin infusion.

Experimental design. 4 groups of animals were studied: SE, SH, GE, and GH. Each experiment consisted of equilibration ( -140 to -40 minutes), basal ( -40 to 0 minutes), and experimental (0 to 180 minutes) periods. 

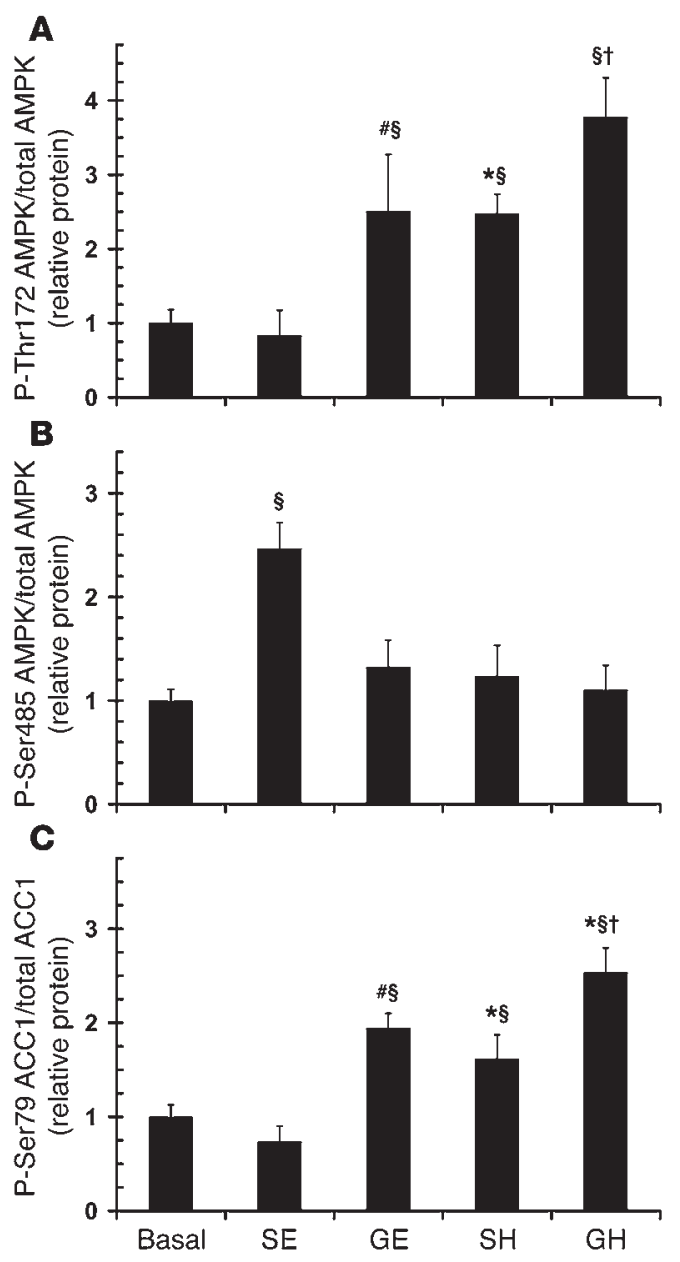

At -140 minutes, a priming dose of $\left[3-{ }^{3} \mathrm{H}\right]$ glucose $(33 \mu \mathrm{Ci})$ was given, followed by a constant infusion of $\left[3{ }^{-3} \mathrm{H}\right]$ glucose $(0.35 \mu \mathrm{Ci} / \mathrm{min})$ and indocyanine green $(0.07 \mathrm{mg} / \mathrm{min})$. The equilibration period was followed by a control period and an experimental period, which was divided into period 1 (0-60 minutes) and period 2 (60-180 minutes). In experimental period 1 , somatostatin $(0.8 \mu \mathrm{g} / \mathrm{kg} / \mathrm{min})$ and intraportal insulin $(5.0 \mathrm{mU} / \mathrm{kg} / \mathrm{min})$ were infused, and glucose was monitored every 5 minutes in order to maintain euglycemia by infusing glucose through the saphenous vein as required ( $20 \%$ dextrose). In experimental period 2 , the somatostatin and insulin infusions were continued, and either glucagon $(2.3 \mathrm{ng} / \mathrm{kg} / \mathrm{min})$ or saline $(0.9 \% \mathrm{NaCl})$ were infused intraportally. Glucose was infused as required to maintain euglycemia $(\sim 100 \mathrm{mg} / \mathrm{dl})$ or to establish hypoglycemia of approximately $50 \mathrm{mg} / \mathrm{dl}$. All animals were euthanized at the end of the experiment, and hepatic biopsies were taken and frozen at $-70^{\circ} \mathrm{C}$. The correct positions of the catheters' tips were also confirmed at autopsy.

Real-time PCR and Western blot analysis. Biopsies from hepatic liver lobes 2, 3 , and 7 were obtained within 2 minutes of the final sampling time point. In each case, the dog was anesthetized with sodium pentobarbital, a laparotomy was used to expose the liver, and approximately $5 \mathrm{~g}$ of each liver lobe was freeze-clamped with tongs cooled in liquid nitrogen. The frozen liver samples were stored at $-70^{\circ} \mathrm{C}$ until subsequent analysis for protein (via Western blotting) and mRNA (via real-time PCR) levels.

Total RNA was extracted by homogenizing $50 \mathrm{mg}$ of frozen canine liver in Tri-reagent (Sigma-Aldrich) following the manufacturer's instructions, and RNA was further purified using the Qiagen RNEasy kit (Qiagen). First-

\section{Figure 7}

AMPK signaling. AMPK phosphorylation at (A) Thr172 (index of activation) and (B) Ser485 (index of inhibition by insulin) and (C) ACC (Ser79) phosphorylation, relative to levels observed in basal control animals. Values are mean $\pm \mathrm{SEM} ; n=3-4$ per group. $\$ P<0.05$ vs. basal; ${ }^{*} P<0.05$ vs. corresponding euglycemic group; ${ }^{\dagger} P<0.05$, GH vs. SH; ${ }^{P} P<0.05$, GE vs. SE.

strand cDNA was synthesized from total RNA using the High Capacity reverse transcription kit (Applied Biosystems). Primer pairs were as follows: PCK1, 5'-AGCTTTCAATGCCCGATTTCCAGG-3' and 5'-TCAGCTCGATGCCGATCTTTGACA-3'; G6PC, 5'-ATGCCTTCTATGTCCTCTTTCC-3' and 5'-GCCAGTCTCCAATCACAGC-3'; hypoxanthine phosphoribosyl transferase 1 (HPRT1), 5'-AGCTTGCTGGTGAAAAGGAC-3' and 5'-TTATAGTCAAGGGCATATCC-3'. Real-time PCR analysis was performed using iQ Supermix reagent (Bio-Rad). Test genes were normalized to the housekeeping gene HPRT1 using the Livak method (31).

For Western blotting, sample preparation (in conditions that inhibited endogenous protease, kinase, and phosphatase activities), electrophoretic separation, blotting, normalization, and immunodetection of proteins was performed essentially as described previously (32). Antibodies specific for total and phosphorylated Akt, GSK3 $\beta$, GS, FOXO1, AMPK, ACC, CREB, STAT, and CRTC2 were purchased from Cell Signaling, while the actin (loading control) and PGC1 $\alpha$ antibodies were purchased from Santa Cruz Biotechnology. The PCK antibody was a gift from D.K. Granner (Vanderbilt University School of Medicine). Test protein bands in the linear signal range were quantified using ImageJ software (http://rsb.info.nih.gov/ij/). Antibody incubation, washing, and exposure conditions were optimized for each antibody individually, as done previously (33). Actin was used as a loading control for all test proteins. Each antibody cross-reacted with 1 canine protein at the appropriate molecular weight. Blots probed with phosphospecific antibodies were stripped and reprobed with antibodies against the respective total protein. Thus, data for phosphoproteins are corrected for the respective total proteins. In the case of PCK and PGC1 $\alpha$, protein levels were normalized against actin.

GS and GP activity determination. GS and GP activity ratios were assessed using standard, established enzyme assays $(34,35)$.

Analytical procedures. Immediately after samples were drawn, 4 10- $\mu$ l aliquots of plasma were analyzed for glucose using the glucose oxidase method in a glucose analyzer (Beckman Instruments). [3- $\left.{ }^{3} \mathrm{H}\right]$ glucose, lactate, alanine, glycerol, $\beta$-hydroxybutyrate, indocyanine green, insulin, glucagon, catecholamines, cortisol, and nonesterified FFAs were determined as previously described $(36,37)$. All samples were placed at $-70^{\circ} \mathrm{C}$ until the assays were completed.

General calculations. Hepatic blood flow was determined by 2 methods: transonic flow probes and indocyanine green. The data shown were calculated using transonic flows, since no assumptions regarding the distribution of flow in the portal vein and hepatic artery were then required. Plasma glucose values were converted to blood glucose values using previously established correction factors (38). Net hepatic balance was determined as previously described (36). Net fractional extraction was calculated as net hepatic balance/load ${ }_{\text {in. }}$. Tracer-determined whole-body glucose production and utilization were measured using a primed, constant infusion of $\left[3-{ }^{3} \mathrm{H}\right]$ glucose. Data calculation was carried out using the 2-compartment model described by Mari (39) and canine parameters reported by Dobbins (40). The approximate plasma insulin and glucagon concentrations in the hepatic sinusoidal bed were calculated as previously described (38).

AUC calculations. The changes caused by saline or glucagon under euglycemic or hypoglycemic conditions were calculated as difference relative to the 60-minute time point (i.e., 60-180 minutes). Therefore, the effect of glucagon in the presence of hyperinsulinemia/euglycemia (GE vs. SE) or hyperinsulinemia/hypoglycemia (GH vs. SH) could be compared. 
NHGNG flux and NHGLY flux calculations. Gluconeogenesis is the synthesis and release of glucose formed from noncarbohydrate precursors. Glucose-6-phosphate produced from flux through the gluconeogenic pathway is not only released as glucose, it can also be stored as glycogen, oxidized, or released as lactate. Therefore, there is a distinction between gluconeogenic flux to glucose-6-phosphate, which is the conversion of precursors to glucose-6-phosphate, and gluconeogenesis per se, which is the release of glucose derived from gluconeogenic flux into the blood. In the present study, we estimated NHGNG flux relative to glucose-6-phosphate and NHGLY flux as described previously (38).

Statistics. Data were analyzed for differences between SE and GE and between SH and GH groups. Statistical comparisons were carried out using 2-way repeated-measures ANOVA and 2-way ANOVA with post-hoc data analysis determined by Student-Newman-Keuls method (Sigma Stat, SPSS Inc.). A $P$ value less than 0.05 was considered significant.

\section{Acknowledgments}

The authors thank Margaret Lautz, Jon Hastings, Susan Hajizadeh, Wanda Snead, Eric Allen, and Patrick Donahue for their excellent technical support and Dale Edgerton and Mary Courtney Moore for their assistance with the manuscript. This work was supported by NIH grants R37 DK18243, R37 DK18243S, and P60 DK020593 to A.D. Cherrington and R37 DK27221 to P.J. Roach. A.D. Cherrington holds The Jacquelyn A. Turner and Dr. Dorothy J. Turner Chair in Diabetes Research, Vanderbilt University Medical School.

Received for publication September 3, 2010, and accepted September 29, 2010.

Address correspondence to: Alan D. Cherrington, Molecular Physiology and Biophysics, Vanderbilt University Medical Center, 702 Light Hall, Nashville, Tennessee 37232-0615, USA. Phone: 615.322.7013; Fax: 615.343.0490; E-mail: alan.cherrington@ vanderbilt.edu.

This work was presented in part at the American Diabetes Association 66th Scientific Sessions, Washington, DC, USA, on June 9-13, 2006.
1. Cryer PE, Davis SN, Shamoon H. Hypoglycemia in diabetes. Diabetes Care. 2003;26(6):1902-1912.

2. Cryer PE. The prevention and correction of hypoglycemia. In: Jefferson L, ed. Handbook of Physiology: The Endocrine Pancreas and Regulation of Metabolism. New York, New York, USA: Oxford University Press; 2001:1057-1092.

3. Steiner KE, Williams PE, Lacy WW, Cherrington AD. Effects of insulin on glucagon-stimulated glucose production in the conscious dog. Metabolism. 1990;39(12):1325-1333.

4. Dobbins RL, Connolly CC, Neal DW, Palladino LJ, Parlow AF, Cherrington AD. Role of glucagon in countering hypoglycemia induced by insulin infusion in dogs. Am J Physiol. 1991;261(6 pt 1):E773-E781.

5. Ramnanan CJ, et al. Molecular characterization of insulin-mediated suppression of hepatic glucose production in vivo. Diabetes. 2010;59(6):1302-1311.

6. Gerich J, et al. Hormonal mechanisms of recovery from insulin-induced hypoglycemia in man. Am J Physiol. 1979;236(4):E380-E385.

7. Cryer PE, Tse TF, Clutter WE, Shah SD. Roles of glucagon and epinephrine in hypoglycemic and nonhypoglycemic glucose counterregulation in humans. Am J Physiol. 1984;247(2 pt 1):E198-E205.

8. Taborsky GJ Jr, Ahren B, Havel PJ. Autonomic mediation of glucagon secretion during hypoglycemia: implications for impaired alpha-cell responses in type 1 diabetes. Diabetes. 1998;47(7):995-1005.

9. Havel PJ, et al. Redundant parasympathetic and sympathoadrenal mediation of increased glucagon secretion during insulin-induced hypoglycemia in conscious rats. Metabolism. 1994;43(7):860-866.

10. Connolly CC, et al. Regulation of lipolysis and ketogenesis by norepinephrine in conscious dogs. Am J Physiol. 1991;261(4 pt 1):E466-E472.

11. Steiner KE, Fuchs H, Williams PE, Stevenson RW, Cherrington AD, Alberti KG. Regulation of ketogenesis by epinephrine and norepinephrine in the overnight-fasted, conscious dog. Diabetes. 1985;34(5):425-432.

12. Sacca L, Cryer PE, Sherwin RS. Blood glucose regulates the effects of insulin and counterregulatory hormones on glucose production in vivo. Diabetes. 1979;28(6):533-536.

13. Bolli G, et al. Role of hepatic autoregulation in defense against hypoglycemia in humans. J Clin Invest. 1985;75(5):1623-1631.

14. Ruderman NB, Herrera MG. Glucose regulation of hepatic gluconeogenesis. Am J Physiol. 1968; 214(6):1346-1351.

15. Glinsmann WH, Hern EP, Lynch A. Intrinsic regu- lation of glucose output by rat liver. Am J Physiol. 1969;216(4):698-703.

16. McCraw EF, Peterson MJ, Ashmore J. Autoregulation of glucose metabolism in the isolated perfused rat liver. Proc Soc Exp Biol Med. 1967;126(1):232-236.

17. Eigler N, Sacca L, Sherwin RS. Synergistic interactions of physiologic increments of glucagon, epinephrine, and cortisol in the dog: a model for stress-induced hyperglycemia. J Clin Invest. 1979;63(1):114-123.

18. Shamoon H, Hendler R, Sherwin RS. Synergistic interactions among antiinsulin hormones in the pathogenesis of stress hyperglycemia in humans. J Clin Endocrinol Metab. 1981;52(6):1235-1241.

19. Lecavalier L, Bolli G, Gerich J. Glucagon-cortisol interactions on glucose turnover and lactate gluconeogenesis in normal humans. Am J Physiol. 1990;258(4 pt 1):E569-E575.

20. Gustavson SM, et al. Interaction of glucagon and epinephrine in the control of hepatic glucose production in the conscious dog. Am J Physiol Endocrinol Metab. 2003;284(4):E695-E707.

21. Berglund ED, et al. Hepatic energy state is regulated by glucagon receptor signaling in mice. J Clin Invest. 2009;119(8):2412-2422.

22. Camacho RC, Lacy DB, James FD, Donahue EP, Wasserman DH. 5-Aminoimidazole-4-carboxamide-1-beta-D-ribofuranoside renders glucose output by the liver of the dog insensitive to a pharmacological increment in insulin. Am J Physiol Endocrinol Metab. 2005;289(6):E1039-E1043.

23. Vernia S, et al. AMP-activated protein kinase phosphorylates R5/PTG, the glycogen targeting subunit of the R5/PTG-protein phosphatase 1 holoenzyme, and accelerates its down-regulation by the laforin-malin complex. J Biol Chem. 2009; 284(13):8247-8255.

24. Carling D, Hardie DG. The substrate and sequence specificity of the AMP-activated protein kinase. Phosphorylation of glycogen synthase and phosphorylase kinase. Biochim Biophys Acta. 1989;1012(1):81-86.

25. Ros S, Garcia-Rocha M, Dominguez J, Ferrer JC, Guinovart JJ. Control of liver glycogen synthase activity and intracellular distribution by phosphorylation. J Biol Chem. 2009;284(10):6370-6378.

26. Mankouri J, et al. Enhanced hepatitis C virus genome replication and lipid accumulation mediated by inhibition of AMP-activated protein kinase. Proc Natl Acad Sci U S A. 2010;107(25):11549-11554.

27. Hurley RL, et al. Regulation of AMP-activated protein kinase by multisite phosphorylation in response to agents that elevate cellular cAMP. J Biol Chem. 2006;281(48):36662-36672.

28. Koo SH, et al. The CREB coactivator TORC2 is a key regulator of fasting glucose metabolism. Nature. 2005;437(7062):1109-1111.

29. Dobbins RL, Davis SN, Neal DW, Cobelli C, Jaspan J, Cherrington AD. Compartmental modeling of glucagon kinetics in the conscious dog. Metabolism. 1995;44(4):452-459.

30. Myers SR, McGuinness OP, Neal DW, Cherrington $\mathrm{AD}$. Intraportal glucose delivery alters the relationship between net hepatic glucose uptake and the insulin concentration. J Clin Invest. 1991;87(3):930-939.

31. Livak KJ, Schmittgen TD. Analysis of relative gene expression data using real-time quantitative PCR and the 2(-Delta Delta $\mathrm{C}(\mathrm{T}))$ Method. Methods. 2001;25(4):402-408.

32. Ramnanan CJ, Storey KB. Glucose-6-phosphate dehydrogenase regulation during hypometabolism. Biochem Biophys Res Commun. 2006;339(1):7-16.

33. Edgerton DS, et al. Effects of insulin on the metabolic control of hepatic gluconeogenesis in vivo. Diabetes. 2009;58(12):2766-2775.

34. Thomas JA, Schlender KK, Larner J. A rapid filter paper assay for UDPglucose-glycogen glucosyltransferase, including an improved biosynthesis of UDP-14C-glucose. Anal Biochem. 1968; 25(1):486-499.

35. Guinovart JJ, Salavert A, Massague J, Ciudad CJ, Salsas E, Itarte E. Glycogen synthase: a new activity ratio assay expressing a high sensitivity to the phosphorylation state. FEBS Lett. 1979;106(2):284-288.

36 . Rivera $\mathrm{N}$, et al. A novel glucagon receptor antagonist, NNC 25-0926, blunts hepatic glucose production in the conscious dog. J Pharmacol Exp Ther. 2007;321(2):743-752.

37. Edgerton DS, et al. Small increases in insulin inhibit hepatic glucose production solely caused by an effect on glycogen metabolism. Diabetes. 2001;50(8):1872-1882.

38. Edgerton DS, et al. Effects of hyperglycemia on hepatic gluconeogenic flux during glycogen phosphorylase inhibition in the conscious dog. Am J Physiol Endocrinol Metab. 2004;286(4):E510-E522.

39. Mari A. Estimation of the rate of appearance in the non-steady state with a two-compartment model. Am J Physiol. 1992;263(2 pt 1):E400-E415.

40. Dobbins RL, Davis SN, Neal DW, Cobelli C, Cherrington AD. Pulsatility does not alter the response to a physiological increment in glucagon in the conscious dog. Am J Physiol. 1994; 266(3 pt 1):E467-E478. 